\title{
The median effective effect-site concentration of remifentanil for minimizing the cardiovascular changes to endotracheal intubation during desflurane anesthesia in pediatric patients
}

Eun-Jung Kim, Sang-Wook Shin, Tae-Kyun Kim, Ji-Uk Yoon, Gyeong-Jo Byeon, and Hye-Jin Kim

Department of Anesthesiology and Pain Medicine, Pusan National University School of Medicine, Yangsan, Korea

Background: Desflurane has the most rapid onset and offset of action among the volatile anesthetic agents used for general anesthesia, but it can cause airway reactivity, tachycardia, and hypertension during induction, especially in pediatric patients. This study was designed to determine a median effective effect-site concentration $\left(\mathrm{EC}_{50}\right)$ of remifentanil to prevent the cardiovascular changes due to tracheal intubation during the 1 minimum alveolar concentration (MAC) desflurane inhalation, which was required to prevent movement in response to a noxious stimulus in $50 \%$ of subjects, in pediatric patients.

Methods: Twenty-four pediatric patients between the ages 5-15 years were enrolled in this study. We injected thiopental intravenously, at the same time remifentanil was infused by Target Controlled Infusion (TCI) device. When the target effect-site concentration (Ce) of remifentanil reached a preset level, desflurane was administrated through the facial mask. Then, we assessed the signs of desflurane related airway reactivity and cardiovascular changes for $2 \mathrm{~min}$. The up-and-down criteria was a $20 \%$ change in systolic blood pressure (SBP) and a heart rate (HR) between just prior to intubation and $1 \mathrm{~min}$ after intubation. The $\mathrm{EC}_{50}$ of remifentanil was calculated from 8 independent pairs using Dixon's up-and-down method.

Results: We studied 24 pediatric patients in range of $1-5 \mathrm{ng} / \mathrm{ml}$ of the Ce of remifentanil. No patient showed airway reactivity during the study. The $\mathrm{EC}_{50}$ of remifentanil to suppress the hemodynamic changes after tracheal intubation during desflurane anesthesia was calculated as $3.4 \pm 0.9 \mathrm{ng} / \mathrm{ml}$.

Conclusions: In pediatric anesthesia, the $\mathrm{EC}_{50}$ of remifentanil to minimize the cardiovascular changes due to tracheal intubation during 1 MAC desflurane anesthesia was $3.4 \pm 0.9 \mathrm{ng} / \mathrm{ml}$. (Korean J Anesthesiol 2012; 63: 314-320)

Key Words: Child, Desflurane, Endotracheal intubation, Heart rate, Remifentanil, Systolic pressure.

Received: March 22, 2012. Revised: 1st, May 9, 2012; 2nd, May 10, 2012; 3rd, May 11, 2012. Accepted: May 16, 2012.

Corresponding author: Sang-Wook Shin, M.D., Department of Anesthesiology and Pain Medicine, Pusan National University School of Medicine, Beomeo-ri, Mulgeum-eup, Yangsan 626-770, Korea. Tel: 82-55-360-2129, Fax: 82-55-360-2149, E-mail: shinsw@pusan.ac.kr (c) This is an open-access article distributed under the terms of the Creative Commons Attribution Non-Commercial License (http:// creativecommons.org/licenses/by-nc/3.0/), which permits unrestricted non-commercial use, distribution, and reproduction in any medium, provided the original work is properly cited. 


\section{Introduction}

Desflurane has the most rapid onset and offset of action among the volatile anesthetic agents used for general anesthesia, as it has low solubility in blood and body tissues. These properties of desflurane predict rapid induction and recovery from general anesthesia with its use [1]. However, anesthesia induction with desflurane is troublesome because desflurane can cause airway reactivity, tachycardia, and hypertension when inhaled at induction levels with higher concentrations, especially in pediatric patients $[2,3]$.

In pediatric anesthesia, laryngoscopy and tracheal intubation increase the catecholamine level, SBP, and HR temporarily [4]. Such transient change in cardiovascular responses can cause hazardous effects in the patients with pulmonary hypertension, cerebral vascular malformation and increased intracranial pressure $[5,6]$. Suppression of the cardiovascular responses to desflurane itself as well as to tracheal intubation and airway reactivity are required to adapt the concept of balanced anesthesia during induction with desflurane [7].

Remifentanil is a short acting opioid and is quickly hydrolyzed by nonspecific esterase in the plasma and the multiorgans [8]. The time-to-peak effect of remifentanil is $1.6 \mathrm{~min}$ so remifentanil is considered to be effective in the suppression of cardiovascular changes to abrupt stimulation, such as laryngoscopy and tracheal intubation [9]. In addition, there is a study about the optimal dose of remifentanil to minimize cardiovascular changes to tracheal intubation in adults [10].

In pediatric patients, few studies have been performed on the optimal dose of remifentanil during induction of anesthesia, particularly in the case of desflurane anesthesia. Therefore, this study was designed to determine a median effective effect-site concentration $\left(\mathrm{EC}_{50}\right)$ of remifentanil to prevent the cardiovascular changes to tracheal intubation during the 1 MAC desflurane inhalation in pediatric patients. Furthermore, the desflurane related airway reactivity and remifentanil related complications were evaluated in this study.

\section{Materials and Methods}

After the approval of the hospital Institutional Review Board, informed consent was obtained from the patients and the guardians of the patients. American Society of Anesthesiologists (ASA) physical status class I pediatric patients between ages 5-15 years, who were scheduled for elective surgery, were enrolled in this study. The patients' demographic data are presented in Table 1. The patients were excluded if they had a recent history of upper respiratory tract infection, upper airway deformation, anticipated to have difficulty with laryngoscopy, and if tracheal intubation had to be attempted twice or more because of difficult intubation. An aliquot of $5 \mu \mathrm{g} / \mathrm{kg}$ glycopyrrolate was administered intramuscularly as premedication, $30 \mathrm{~min}$ before induction of anesthesia.

When the patient arrived into the operating room, we applied standard monitoring such as pulse oximetry, electrocardiography and noninvasive blood pressure. After preoxygenation with $5 \mathrm{~L} / \mathrm{min}$ of $100 \%$ oxygen, $4 \mathrm{mg} / \mathrm{kg}$ of thiopental sodium was administered intravenously. At the same time, $1 \mathrm{mg}$ remifentanil was diluted into $50 \mathrm{ml}$ of normal saline $(20 \mu \mathrm{g} / \mathrm{ml}$ solution) and was infused by TCI via syringe pump (Pilot Anesthesia 2. Fresenius vial, France) controlled by an Asan pump (2.0.7 version, Bionet Co., Ltd, Seoul, Korea) using the pharmacokinetic model of Minto and colleague [11]. We started to infuse remifentanil at $1 \mathrm{ng} / \mathrm{ml}$ and increased the Ce of remifentanil by $1 \mathrm{ng} / \mathrm{ml}$ until the concentration reached at target Ce level. As soon as a patient lost consciousness, his or her ventilation was assisted with $5 \mathrm{~L} / \mathrm{min}$ of $100 \%$ oxygen. After the Ce of remifentanil reached the target concentration level, we opened the dial of desflurane vaporizer at 8 vol\%.

During the desflurane inhalation, we assessed the signs of desflurane-related airway reactivity (cough, secretion, laryngospasm and bronchospasm) and tachycardia (HR > 140 beats/min), bradycardia (HR $<60$ beats $/ \mathrm{min}$ ), hypertension (SBP $>130 \mathrm{mmHg}$ ) and hypotension (SBP $<80 \mathrm{mmHg}$ ) for $2 \mathrm{~min}$ [12]. Then, $0.2 \mathrm{mg} / \mathrm{kg}$ cisatracurium was injected into

Table 1. Characteristics of Patients

\begin{tabular}{lccc}
\hline & Success & Failure & P value \\
\hline Number of patients & 12 & 12 & $6 / 6$ \\
Sex (M/F) & $9 / 3$ & $10.3 \pm 0.6$ & 0.4766 \\
Age $(\mathrm{yr})$ & $10.3 \pm 0.6$ & $43.3 \pm 5.3$ & 0.4345 \\
Weight $(\mathrm{kg})$ & $37.9 \pm 4.2$ & $141.6 \pm 4.6$ & 0.8032 \\
Height $(\mathrm{cm})$ & $143.2 \pm 4.3$ & $2.6 \pm 0.3$ & 0.0125 \\
Target remifentanil concentration $(\mathrm{ng} / \mathrm{ml})$ & $3.6 \pm 0.3$ & None & \\
Airway reactivity & None & . & \\
\hline
\end{tabular}

Values are presented as mean \pm SD or number of patients, as appropriate. A success response was defined as less than $20 \%$ changes in heart rate (HR) and systolic blood pressure (SBP) at $1 \mathrm{~min}$ after intubation compared to those of just prior to tracheal intubation. A failure response was defined as changes in HR or SBP at 1 min after tracheal intubation that did not exceed 20\% of the values just before tracheal intubation. M: male, F: female, Airway reactivity: cough, secretion, laryngospasm, and bronchospasm. 
the patient, and tracheal intubation was performed 2 min later, using a curved laryngoscope. After tracheal intubation, a patient was mechanically ventilated with desflurane 6 vol\% and $2 \mathrm{~L} / \mathrm{min}$ of fresh gas flow with $50 \%$ oxygen in air. The ventilator settings were individualized (tidal volume $=8 \mathrm{ml} / \mathrm{kg}$, frequency $=15-25 / \mathrm{min}$ ). The SBP, diastolic blood pressure (DBP), mean blood pressure (MBP), $\mathrm{HR}, \mathrm{SpO}_{2}$, end tidal concentrations of carbon dioxide $\left(\mathrm{EtCO}_{2}\right)$ and desflurane (EtDES) were measured at different time points, such as at the time before anesthesia induction (B), when the target effect-site concentration was reached (tCe), 1 min after desflurane inhalation (D1), 2 min after desflurane inhalation (D2), before tracheal intubation (BI), just after tracheal intubation (I0), 1 min after tracheal intubation (I1), and 3 min after tracheal intubation (I3). The rescue regimens were prepared to treat the side effects of remifentanil or desflurane: $0.01 \mathrm{mg} / \mathrm{kg}$ atropine for bradycardia and $0.1 \mathrm{mg} / \mathrm{kg}$ ephedrine for hypotension.

The $\mathrm{EC}_{50}$ of remifentanil for preventing the cardiovascular changes after tracheal intubation was determined by Dixon's up-and-down method. We started to infuse the remifentanil at $4 \mathrm{ng} / \mathrm{ml}$, changed the target Ce of remifentanil that was determined with the response of each patient. A success response was defined as changes of HR and SBP at 1 min after tracheal intubation that did not exceed $20 \%$ of the figure just before tracheal intubation. If the study appeared to have a successful response, then the Ce of remifentanil was lowered by $1 \mathrm{ng} / \mathrm{ml}$ for the next patient but in the opposite, the Ce of remifentanil was increased by $1 \mathrm{ng} / \mathrm{ml}$. A change between consecutive success and failure response was termed a "crossover" with a midpoint concentration between the success and failure response concentrations. This study was ended after 8 crossovers had occurred. The 8 crossovers were averaged to find the $\mathrm{EC}_{50}$ of remifentanil.

The patients were divided into a success and a failure group according to the response at $1 \mathrm{~min}$ after tracheal intubation. The characteristics of patients were compared using the Chisquare test or the t-test. For comparing the repeated measured hemodynamic values between the 2 groups, we used a 2-way repeated measures ANOVA. A probit analysis was used for calculation of $\mathrm{EC}_{50}, \mathrm{EC}_{95}$ (the effect-site concentration of remifentanil for preventing response to particular stimulus in $95 \%$ patients), and the confidence interval. The data is presented as means \pm SDs. SPSS (version 13. SPSS Inc., Chicago, IL, USA) was used for the statistical analysis; a $\mathrm{P}$ value $<0.05$ was considered as statistically significant.

\section{Results}

A total of 24 patients were enrolled into this study. The success and failure groups included 12 patients each. There were no significant differences between the success and failure group for gender, age, weight or height.

The $\mathrm{EC}_{50}$ of remifentanil to suppress the cardiovascular changes after tracheal intubation in desflurane anesthesia in pediatric patients was calculated as $3.4 \pm 0.9 \mathrm{ng} / \mathrm{ml}$ from this study (Fig. 1). This value was figured out by averaging the eight crossovers.

The time sequential comparison of the changes in the HR, SBP, DBP, MBP between the success and failure group were presented in Fig. 2. The increase in HR at I0, I3 was significantly less in the success group. The increase of SBP was significantly less in the success group at I0, I1. The increase of DBP, MBP was significantly less in the success group at D2, I0, I1 ( $<<0.05)$.

In probit analysis, the $\mathrm{EC}_{50}$ and $\mathrm{EC}_{95}$ of remifentanil were 3.08 $\mathrm{ng} / \mathrm{ml}[95 \%$ confidence interval (CI), 1.8-4.4] and $5.15 \mathrm{ng} / \mathrm{ml}$ [95\% CI, 4.1-16.1] (Fig. 3).

In the present study, one patient produced hypertension at the point of I0 and a second revealed hypertension at the points of I0, I1 in the failure group. Any complications related to desflurane-associated airway reactivity (cough, secretion, laryngospasm and bronchospasm) were not observed in any patient during the study. None of the side effects of remifentanil (respiratory depression, muscle rigidity, pruritus, shivering, bradycardia, hypotension) occurred during this study.

\section{Discussion}

In the past, a high incidence of moderate to severe laryngo-

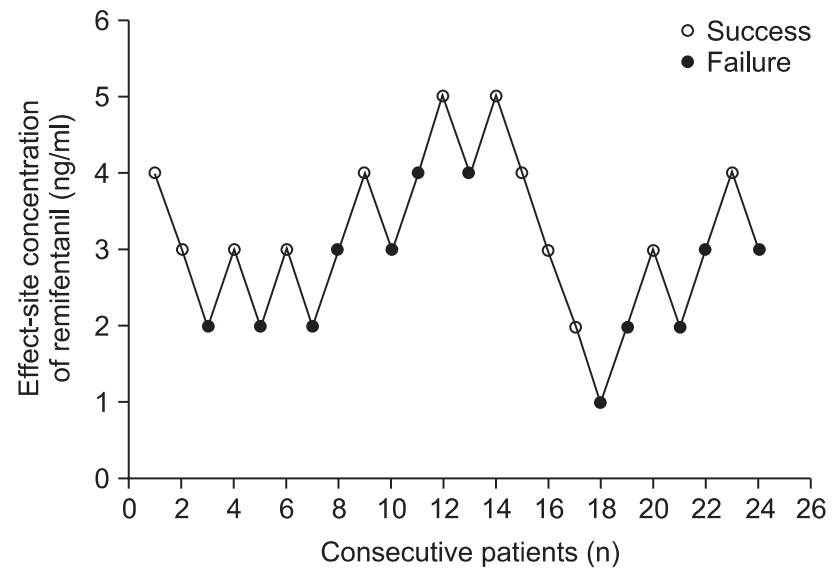

Fig. 1. Up-and-down sequence. A success response was defined as less than $20 \%$ changes in heart rate (HR) and systolic blood pressure (SBP) at 1 min after tracheal intubation compared to those of just before tracheal intubation. If the HR or SBP change exceeded $20 \%$, then it was defined as a failure response. A change between consecutive success and failure responses is a "crossover" with a midpoint concentration between the success and failure response concentration. Eight crossovers were averaged to determine the median effective effect-site concentration of remifentanil. 

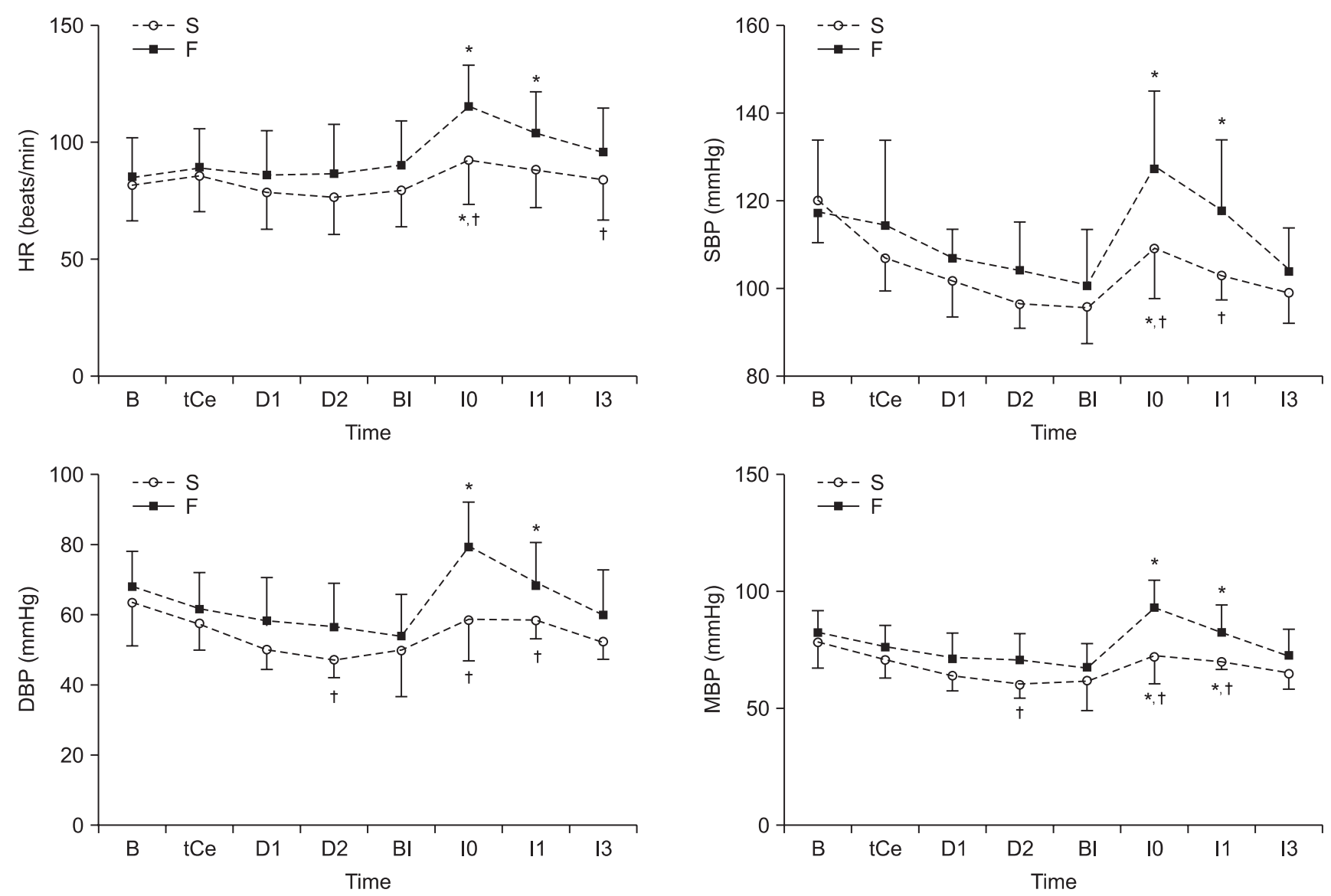

Fig. 2. Time sequential comparison of the changes in the heart rate (HR), systolic blood pressure (SBP), diastolic blood pressure (DBP), and mean blood pressure (MBP) between the success and failure groups. The success group includes the patients with changes in HR and SBP at 1 min after intubation that did not exceed $20 \%$ of the value just before tracheal intubation. If the HR or SBP at 1 min after tracheal intubation exceeded $20 \%$ of the value just before tracheal intubation, the particular patient was included in the failure group. S: success group, F: failure group, B: the time before anesthesia induction, tCe: the time when the target effect site concentration was reached, D1: the time 1 min after desflurane inhalation, D2: the time 2 min after desflurane inhalation, BI: the time before tracheal intubation, I0: the time just after tracheal intubation, I1: the time $1 \mathrm{~min}$ after tracheal intubation, I3: the time 3 min after tracheal intubation. $* \mathrm{P}<0.05$ compared with the BI value, ${ }^{\dagger} \mathrm{P}<$ 0.05 compared with the failure group.

spasm, coughing, breath holding and secretions were unfavorable side effects that occurred during induction with desflurane in pediatric patients [3]. Opioids may have decreased these side effects; Ahn et al. [13] stated that a continuous remifentanil infusion reduced airway reactivity and stabilized hemodynamics during desflurane inhalation. Lee and Jung [14] stated that the $\mathrm{EC}_{50}$ of remifentanil to block the hemodynamic response to tracheal intubation was $3.7 \mathrm{ng} / \mathrm{ml}$ during inhalational induction with 1 MAC desflurane in adults. There have been studies on determining the optimal bolus dose of remifentanil to attenuate cardiovascular changes in pediatric patients. Yoon et al. [15] stated that a bolus injection of $2 \mu \mathrm{g} /$ $\mathrm{kg}$ remifentanil was a dosage to attenuate the cardiovascular responses after intubation in pediatric patients. Xue et al. [16] stated that bolus administration of remifentanil 1 or $1.25 \mu \mathrm{g} /$ $\mathrm{kg}$ is effective for attenuation of the cardiovascular intubation response in pediatric patients when anesthesia is induced using $2.5 \mathrm{mg} / \mathrm{kg}$ propofol and $0.1 \mathrm{mg} / \mathrm{kg}$ vecuronium. In this study, we could demonstrate that the continuous administration of remifentanil was beneficial to stabilize hemodynamic responses and to suppress airway irritation during inhalation induction with desflurane. This study, using Dixon's up-and-down method, showed that the $\mathrm{EC}_{50}$ of the remifentanil to minimize cardiovascular changes after intubation and when combined with 1 MAC of desflurane in pediatric patients is $3.4 \pm 0.9 \mathrm{ng} / \mathrm{ml}$.

We employed cisatracurium as a muscle relaxant for tracheal intubation because of aminosteroidal neuromuscular blocking agents, such as rocuronium and vecuronium that lead directly to pain by activating the C-nociceptor [17]. The pain from rocuronium injection during anesthesia induction may induce brick flexion of the elbow and wrist or generalized movement in particular pediatric patients [18]. Rocuronium injection 
pain has an effect on cardiovascular changes of increasing HR, blood pressure (BP) and displacement of intravenous catheter that can be harmful to pediatric patients during the induction. Park et al. [19] stated that the $\mathrm{EC}_{50}$ of remifentanil for preventing rocuronium injection pain was higher in children than in other age groups. In that research, the $\mathrm{EC}_{50}$ of remifentanil for preventing rocuronium induced withdrawal movements was $2.8 \pm 0.8 \mathrm{ng} / \mathrm{ml}$ in the children's group (6-12 yr). If we used rocuronium for tracheal intubation, the HR, BP could be changed at a Ce of 1,2 ng/ml dose of remifentanil and the result of a success or failure response could be altered as well.

To deliver a stable analgesic concentration of remifentanil, we adapted the TCI device. TCI targeting Ce are more prone to cause complications because they permit an overshoot of the plasma drug concentration to achieve the target Ce rapidly [20]. Lee et al. [21] demonstrated the safety of pretreatment infusion at considerably high concentrations, even at a target Ce of $6 \mathrm{ng} / \mathrm{ml}$ (to achieve this target concentration, the plasma concentration of remifentanil reaches about $18 \mathrm{ng} / \mathrm{ml}$ ). In this study, owing to overshooting of remifentanil could be dangerous in pediatric patients; just in case, we started to administer remifentanil at $1 \mathrm{ng} / \mathrm{ml}$ and increased the Ce of remifentanil by $1 \mathrm{ng} / \mathrm{ml}$ until the concentration reached at target Ce level. There was no complication related to the high concentration of remifentanil, such as chest wall rigidity, bradycardia, or hypotension.

In the present study, the $\mathrm{EC}_{50}$ of remifentanil to minimize the cardiovascular changes due to tracheal intubation was determined by a Dixon's up-and-down method. In this method, simulation studies suggest that a sample size including at least 20-40 patients would offer stable estimates of a target dose for most realistic scenarios [22]. A survey of the current

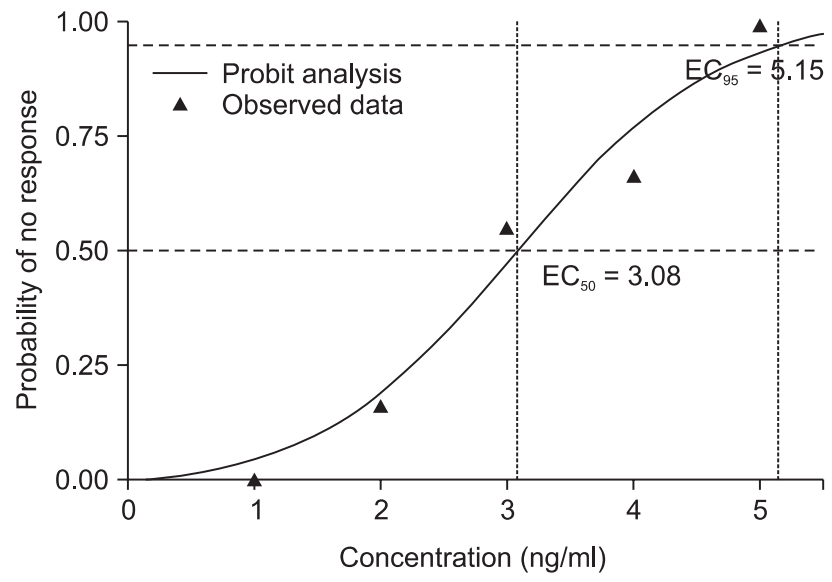

Fig. 3. The effect-site concentration and response curves of remifentanil from probit analysis. $\mathrm{EC}_{50}$ is $3.08 \mathrm{ng} / \mathrm{ml}$ (95\% confidence interval, $1.8-4.4) . \mathrm{EC}_{95}$ is $5.15 \mathrm{ng} / \mathrm{ml}$ (95\% confidence interval, $4.1-$ 16.1). EC: Effect-site concentration. use of up-and-down method in anesthesia study showed that most studies use 20 or more patients in a sequential trial; furthermore, some studies were smaller. Statistical methods articles using simulation methods recommend that studies include 20 or more patients. In addition, we calculated $\mathrm{EC}_{50}$ in 2 ways statistically, a kind of turning point estimator as nonparametric method, logistic/probit estimator as parametric method. In the turning point estimator, the values of successive assigned dose pairs at which the observed response changed direction (pair reversals) are averaged. This method is commonly used in anesthesia up-and-down method studies [23]. The logistic/probit estimator method was criticized for some biases in accuracy. The parameter estimate of the regression slope is biased and the confidence intervals of the $\mathrm{EC}_{50}$ are unrealistically wide. This method adapted ordinarily to the nonindependence of up-and-down data has been developed, but the requirement of tolerance distribution symmetry is necessary [24]. For this reason, Pace and Stylianou [25]. stated that researchers should consider the use of an isotonic regression estimator with confidence intervals derived from boot strapping. It is a well-described variant of restricted least squares regression that constrains the point estimates to be either monotonic increasing or monotonic decreasing [26]. This statistical method may be constant over some range of doses. Thus, we tried to calculate the $\mathrm{EC}_{50}$ and $\mathrm{EC}_{95}$ by an isotonic regression estimator. The $\mathrm{EC}_{50}$ and $\mathrm{EC}_{95}$ derived from the isotonic regression estimator are $2.86 \mathrm{ng} / \mathrm{ml}$ [95\% CI, $2.08-4.1$ ] and $4.85 \mathrm{ng} / \mathrm{ml}$ [95\% CI, 3.89-4.93]. Observed and pooledadjacent-violators algorithm (PAVA) adjusted probability

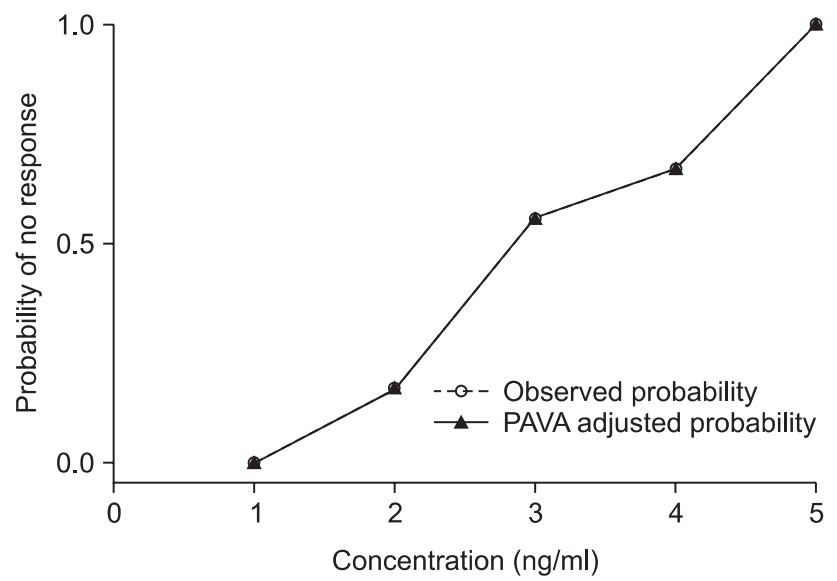

Fig. 4. Observed and pooled-adjacent-violators algorithm (PAVA) adjusted probability in each concentration. The $\mathrm{x}$-axis are the effect-site concentration of remifentanil. The estimate of the observed probability (solid line, open round) and the PAVA adjusted probability (solid line, solid triangle) at the effect-site concentration of remifentanil are plotted on the y-axis. Observed and PAVA adjusted probability graphs have overlapped each other because there were no violations of probability against the dose elevations. 
graphs overlap each other, because there were no violations of probability against the dose elevations (Fig. 4). Even though the probit analysis shows a well-defined graph in this study, the confidence intervals of the $\mathrm{EC}_{95}$ resulted in unrealistically-wide confidence intervals. The isometric regression estimator was superiority than probit analysis in terms of confidence intervals, as it is calculated from the results of a boot strapping method and shows more acceptable ranges of confidence intervals.

The current study has several limitations. First, volatile induction and maintenance anesthesia (VIMA) may be needed occasionally when a pediatric patient has no intravenous route. So $\mathrm{EC}_{50}$ of remifenatnil for suppressing hemodynamic changes during VIMA with desflurane in pediatric patients is critical clinically. Nevertheless, in this study, desflurane inhalation was began after intravenous anesthetics administration on account that pediatric patients are not able to bear the pungency of desflurane in the awake state. Second, there have been few studies that researched the pharmacodynamics and pharmacokinetics of remifentanil in the pediatric patient. For this reason, use of the TCI device is unreliable in pediatric patient. On the other hand, Anderson [27] stated that remifentanil is rapidly cleared by plasma esterase, which is expressed at birth in the pediatric patient in great quantities and its short, unique, context-sensitive half-life is constant, even in small children and neonates. Accordingly, remifentanil doses can be based on pharmacokinetic parameter estimates that were derived from adults. The volume of distribution, central compartment volume, or the elimination half-life of remifentanil remained constant in spite of wide variations in patient age. Third, the ages of the pediatric patients who enrolled in this study varied widely. The age related differences in the remifentanil clearance rate and the volume of distribution could affect the effect site concentration during the study [28]. Moreover, airway reactivity is known to change based on age. Age-related change in bronchial reactivity occurs during childhood, possibly reflecting early changes in airway smooth muscle maturity and later changes in airway wall rigidity [29].

In conclusion, the $\mathrm{EC}_{50}$ of remifentanil to minimize the cardiovascular changes to tracheal intubation during 1 MAC desflurane anesthesia was $3.4 \pm 0.9 \mathrm{ng} / \mathrm{ml}$ by the Turning Point Estimator in pediatric patients. In probit analysis, $\mathrm{EC}_{50}, \mathrm{EC}_{95}$ of remifentanil was $3.08 \mathrm{ng} / \mathrm{ml}$ [95\% CI, 1.8-4.4] and $5.15 \mathrm{ng} /$ $\mathrm{ml}$ [95\% CI, 4.1-16.1]. In pediatric patients, during induction with desflurane combined with remifentanil infusion, there was cardiovascular stability and no airway reactivity.

\section{References}

1. Eger EI 2nd. New inhaled anesthetics. Anesthesiology 1994; 80: 90622.
2. Weiskopf RB, Moore MA, Eger EI 2nd, Noorani M, McKay L, Chortkoff $\mathrm{B}$, et al. Rapid increase in desflurane concentration is associated with greater transient cardiovascular stimulation than with rapid increase in isoflurane concentration in humans. Anesthesiology 1994; 80: 1035-45.

3. TerRiet MF, DeSouza GJ, Jacobs JS, Young D, Lewis MC, Herrington C, et al. Which is most pungent: isoflurane, sevoflurane or desflurane? Br J Anaesth 2000; 85: 305-7.

4. Shribman AJ, Smith G, Achola KJ. Cardiovascular and catecholamine responses to laryngoscopy with and without tracheal intubation. Br J Anaesth 1987; 59: 295-9.

5. Blair JM, Hill DA, Wilson CM, Fee JP. Assessment of tracheal intubation in children after induction with propofol and different doses of remifentanil. Anaesthesia 2004; 59: 27-33.

6. Laussen PC, Wessel DL. Anesthesia for congenital heart disease. In Pediatric Anesthesia. 4th ed. Edited by Gregory GA: Philadelphia, Churchill Livingstone. 2002, p 490.

7. Tonner PH. Balanced anaesthesia today. Best Pract Res Clin Anaesthesiol 2005; 19: 475-84.

8. Glass PS, Hardman D, Kamiyama Y, Quill TJ, Marton G, Donn KH, et al. Preliminary pharmacokinetics and pharmacodynamics of an ultra-short-acting opioid: remifentanil (GI87084B). Anesth Analg 1993; 77: 1031-40.

9. Beers R, Camporesi E. Remifentanil update: clinical science and utility. CNS Drugs 2004; 18: 1085-104.

10. Byun SJ, Hwang SH, Kim JH, Ban JS, Min BW. What is the optimal dosage of remifentanil for minimizing the hemodynamic change to tracheal intubation during induction with propofol target controlled infusion? Korean J Anesthesiol 2006; 50: 140-5.

11. Jung JA, Choi BM, Cho SH, Choe SM, Ghim JL, Lee HM, et al. Effectiveness, safety, and pharmacokinetic and pharmacodynamic characteristics of microemulsion propofol in patients undergoing elective surgery under total intravenous anaesthesia. Br J Anaesth 2010; 104: 563-76.

12. Kliegman RM, Behrman RE, Jenson HB, Stanton BMD. Nelson Textbook of Pediatrics. 18th ed. Philadelphia, Saunders Elsevier. 2007, p 389.

13. Ahn ST, Lee JH, Cheong SH, Lee KM, Lee SE, Kim YH, et al. The effect of continuous remifentanil infusion on the airway reactivity during desflurane inhalation. Korean J Anesthesiol 2007; 53: 44852.

14. Lee JW, Jung CW. The target concentration of remifentanil to suppress the hemodynamic response to endotracheal intubation during inhalation induction with desflurane. Korean J Anesthesiol 2011; 60: 12-8.

15. Yoon SH, Kim KH, Seo SH. Dose of remifentanil for minimizing the cardiovascular changes to tracheal intubation in pediatric patients. Korean J Anesthesiol 2010; 59: 167-72.

16. Xue FS, Xu YC, Liu Y, Yang QY, Liao X, Liu KP, et al. Different small-dose remifentanil blunting the cardiovascular response to laryngoscopy and intubation in children: a randomized doubleblind comparison. Eur J Anaesthesiol 2008; 25: 106-12.

17. Blunk JA, Seifert F, Schmelz M, Reeh PW, Koppert W. Injection pain of rocuronium and vecuronium is evoked by direct activation of nociceptive nerve endings. Eur J Anaesthesiol 2003; 20: 245-53.

18. Borgeat A, Kwiatkowski D. Spontaneous movements associated 
with rocuronium: is pain on injection the cause? Br J Anaesth 1997; 79: 382-3.

19. Park SJ, Park HJ, Choi JY, Kang HS, Choi HS. The influence of age and gender on remifentanil EC50 for preventing rocuronium induced withdrawal movements. Korean J Anesthesiol 2010; 58: 244-8.

20. Shafer SL, Gregg KM. Algorithms to rapidly achieve and maintain stable drug concentrations at the site of drug effect with a computer-controlled infusion pump. J Pharmacokinet Biopharm 1992; 20; 147-69.

21. Lee JR, Jung CW, Lee YH. Reduction of pain during induction with target-controlled propofol and remifentanil. Br J Anaesth 2007; 99; 876-80.

22. Stylianou M. Sequential analysis of Durham and Flournoy's biased coin design for phase i clinical trials. Washington, American University, Department of Mathematics and Statistics, College of Arts and Sciences, pp 1-178.

23. Paul M, Fisher DM. Are estimates of MAC reliable? Anesthesiology 2001; 95: 1362-70.
24. Stylianou M, Flournoy N. Dose finding using the biased coin upand-down design and isotonic regression. Biometrics 2002; 58: 1717.

25. Pace NL, Stylianou MP. Advances in and limitations of up-anddown methodology: a précis of clinical use, study design, and dose estimation in anesthesia research. Anesthesiology 2007; 107: 14452.

26. Robertson T, Wright FT, Dykstra RL. Order Restricted Statistical Inference. New York, John Wiley \& Sons. 1988, pp 1-40.

27. Anderson BJ. Pediatric models for adult target-controlled infusion pumps. Paediatr Anaesth 2010; 20: 223-32.

28. Ross AK, Davis PJ, Dear Gd GL, Ginsberg B, McGowan FX, Stiller $\mathrm{RD}$, et al. Pharmacokinetics of remifentanil in anesthetized pediatric patients undergoing elective surgery or diagnostic procedures. Anesth Analg 2001; 93: 1393-401.

29. Mochizuki H, Arakawa H, Tokuyama K, Morikawa A. Effect of age on bronchial reactivity in children with asthma. J Asthma 2006; 43: 25-9. 